\title{
Efeito da Ausência de Trato dos Bezerros de Rebanhos Leiteiros aos Domingos sobre seus Desempenhos até os Seis Meses de Idade
}

\section{Oriel Fajardo de Campos ${ }^{1}$, Marcos Macedo Junqueira², Daniel de Noronha Figueiredo Vieira da Cunha ${ }^{3}$, Rosane Scatamburlo Lizieire ${ }^{4}$}

\begin{abstract}
RESUMO - Vinte quatro bezerros mestiços Holandês x Zebu foram usados para comparar os seguintes tratamentos experimentais: 1) presença do tratador todos os dias da semana; 2) ausência do tratador aos domingos, com compensação na quantidade de leite oferecida (seis litros de leite integral aos sábados e às segundas-feiras); e 3) ausência do tratador aos domingos, sem compensação na quantidade de leite oferecida. Os bezerros receberam quatro litros de leite integral/animal/dia até as oito semanas de idade, quando foram abruptamente desaleitados. A partir da segunda semana de vida, receberam concentrado limitado em $2 \mathrm{~kg} / \mathrm{animal} / \mathrm{dia}$. Conclui-se que: a ausência do tratador aos domingos não afetou o peso vivo (72,3 vs 71,7 kg) e o ganho de peso médio diário (479 vs $451 \mathrm{~g} / \mathrm{animal} / \mathrm{dia})$ aos seis meses de idade e o consumo médio de concentrado durante as dez primeiras semanas de vida (784 vs $732 \mathrm{~g} / \mathrm{animal} / \mathrm{dia}$ ); a compensação na quantidade oferecida de leite resultou em animais mais pesados ao desaleitamento (63,0 vs 58,2 kg), mas não aos seis meses de idade $(114,3$ vs $113,8 \mathrm{~kg})$
\end{abstract}

Palavras-chave: bezerros, gado de leite, manejo, quantidade de leite

\section{Effect of the Absence of Dairy Calves Management on Sundays on theirs Performance up to Six Months of Age}

\begin{abstract}
Twenty-four Holstein x Zebu crossbred calves were used to compare the following experimental treatments: 1) calves management every day of the week, 2) absence of calves management on Sundays, with the compensation of the amount of milk fed ( $6 \mathrm{~kg}$ of whole milk given on Saturdays and on Mondays), and 3) absence of calves management on Sundays without the compensation of the amount of milk fed. Calves were fed $4 \mathrm{~kg}$ of whole milk/animal/day (except for treatment 2) up to 8 weeks of age when they were abruptly weaned. Starter was available to calves since the second week of age and limited to $2 \mathrm{~kg} / \mathrm{animal} / \mathrm{day}$. It was concluded that: (a) the absence of calves management on Sundays did not affect body weight (72.3 vs $71.7 \mathrm{~kg}$ ) and average daily weight gains (479 vs $451 \mathrm{~g} / \mathrm{animal} /$ day) at six months of age, and average starter intake during the first ten weeks of age (784 vs $732 \mathrm{~g} / \mathrm{animal} / \mathrm{day}$ ); (b) the compensation of the amount of milk fed resulted in heavier calves at weaning ( $63.0 \mathrm{vs} 58.2 \mathrm{~kg})$, but not at six month of age $(114.3$ vs $113.8 \mathrm{~kg})$
\end{abstract}

Key Words: amount of milk, calves, dairy cattle, management

\section{Introdução}

As despesas com mão-de-obra representam parcela significativa no custo da criação de bezerros em propriedades leiteiras. Nas indicações atuais de manejo, recomenda-se que os bezerros sejam observados e alimentados todos os dias da semana. Isto faz com que empregados sejam escalados para tratarem dos bezerros aos domingos, o que resulta em folgas ou em pagamentos de horas extras em dobro em relação àquelas pagas em dias normais da semana. Seria extremamente vantajoso se os bezerros pudessem passar os domingos sem a visita do tratador e, em consequiência, sem a dieta líquida. $\mathrm{O}$ fornecimento de concentrado poderia ser compensado pela colocação de maior quantidade no sábado e na segunda-feira. Fica a questão sobre possíveis efeitos adversos deste manejo sobre o desempenho dos animais.

Com base em revisão bibliográfica de artigos publicados entre as décadas de 50 e 70, Appleman et al. (1975) concluíram que esta prática, quando adotada a partir da segunda semana de idade, não traz desvantagens. Há registros, no entanto, de que os ganhos de peso iniciais de animais da raça Holandesa se

\footnotetext{
${ }^{1}$ Pesquisador da Embrapa Gado de Leite, Campo Experimental Santa Mônica, Barão de Juparanã, Valença, RJ. CEP: 27610-000. Bolsista do CNPq. E.mail: oriel@ cnpgl.embrapa.br

2 Técnico de Nível Superior da Embrapa Gado de Leite, Campo Experimental Santa Mônica, Barão de Juparanã, Valença, RJ. CEP: 27610-000. Bolsista do CNPq. E.mail: marcomj@cnpgl.embrapa.br

${ }^{3}$ Graduando em Zootecnia pela UFRRJ e Bolsista de Iniciação Científica do CNPq.

${ }^{4}$ Pesquisadora da Pesagro-RJ, Estação Experimental de Itaguaí, Seropédica, RJ. CEP:23850-000. Bolsista do CNPq. E.mail: eei@ domain.com.br
} 
mostraram menores (Boucque et al., 1971), embora por volta da $12^{\mathrm{a}}$ à $16^{\mathrm{a}}$ semana os pesos dos bezerros passem a ser iguais. Wood et al. (1971), também utilizando animais da raça Holandesa, constataram maior deposição de carne, gordura e ossos em bezerros que não sofreram jejum, mas os ganhos não diferiram estatisticamente. Os autores autores também verificaram maior peso dos fígados dos animais que passaram por jejum de 24 horas, explicado pelo maior estoque de glicogênio nesse órgão.

O objetivo deste trabalho foi comparar o sistema tradicional em que se considerou a presença do tratador alimentando bezerros de rebanhos leiteiros, até os seis meses de idade todos os dias da semana, com a ausência de trato aos domingos, compensando-se ou não a quantidade de leite não fornecida nesse dia.

\section{Material e Métodos}

O presente experimento foi conduzido no Campo Experimental Santa Mônica, da Embrapa Gado de Leite, localizado em Valença, RJ, no período de 27/04/2001 a 04/02/2002.

Foram utilizados 24 bezerros desde o nascimento até os 180 dias de idade, oito por tratamento experimental, blocados por sexo e peso ao nascer. Os bezerros foram mantidos em abrigos individuais no campo até os 70 dias de idade, distanciados entre si o suficiente para evitar o contato entre eles. Dos 70 aos 180 dias de idade, os animais eram mantidos juntos em piquetes de capim-estrela dotados de cochos, bebedouros e sombra.

Os bezerros permaneceram com suas mães durante as primeiras 24 horas de vida, tendo os tratadores induzido os bezerros a mamarem o colostro mais cedo, quando possível nas primeiras duas horas após o nascimento. Colostro fresco e integral (sem diluição), de preferência de vacas multíparas, foi fornecido até o terceiro dia de idade, na quantidade de 4 litros/animal/dia, em duas refeições. Do quarto ao décimo dia de idade, os animais receberam o leite em duas refeições diárias. A partir daí, a dieta líquida de 4 litros/animal/dia foi fornecida em uma só refeição pela manhã. Após o fornecimento da dieta líquida, não foi disponibilizada água aos bezerros por 30 minutos. O desaleitamento se deu, de forma abrupta, aos 56 dias de idade dos animais.

Os tratamentos experimentais foram: trato todos os dias da semana (controle); ausência de trato aos domingos, com compensação na quantidade de leite; ausência de trato aos domingos, sem compensação na quantidade de leite.

Os animais do segundo tratamento receberam, nos sábados e às segundas-feiras, seis litros de dieta líquida para compensar os quatro litros de leite não recebidos no domingo. Já os animais do terceiro tratamento não tiveram esta compensação, reduzindo a quantidade total de leite gasta em sua criação.

Durante a fase nos abrigos individuais, os animais dos dois tratamentos que não recebiam trato aos domingos eram alocados em área distante e sem comunicação com aqueles do tratamento controle.

Os bezerros receberam, a partir da segunda semana de idade, à vontade, concentrado comercial inicial para bezerros, com $87 \%$ de matéria seca (mínima), 16\% de proteína bruta (mínima), 6,7\% de matéria fibrosa (máximo), 1,5\% de cálcio (máximo) e 0,4\% de fósforo (mínimo), sendo estas informações do fabricante. Aos sábados, foi colocada, à disposição, maior quantidade de concentrado para suprir a ausência de trato aos domingos.

Os animais foram pesados ao nascer e aos dois primeiros dias de vida, considerando-se como peso inicial a média dessas três pesagens. Do mesmo modo, os pesos médios desses animais aos 56,70 e 180 dias de idade foram obtidos de três pesagens consecutivas nessas datas. Além disso, os animais foram pesados a cada sete dias, sendo que todas as pesagens mencionadas iniciaram-se às $7 \mathrm{~h} 30$, antes da alimentação matinal.

Os consumos diários de leite e de concentrado inicial foram estabelecidos, para cada animal, mediante diferença entre as quantidades de matéria natural oferecidas e as sobras.

Diariamente, foram anotadas as consistências das fezes de cada bezerro, registrando-se 1 para fezes normais e 2 para diarréia. O controle de medicações foi realizado em um caderno, registrando-se o número do animal, a data da medicação, o diagnóstico e a medicação realizada.

O delineamento estatístico adotado para ganho de peso e consumo de concentrado foi o de blocos casualizados, com três tratamentos e oito repetições por tratamento. A variável peso vivo foi analisada como parcelas subdivididas, tendo-se os tratamentos experimentais como parcelas e as semanas de idade como subparcelas. A ocorrência de diarréias foi analisada pelo método qui-quadrado, adotando-se, para todas as análises estatísticas, os procedimentos descritos por Gomes (1990).

\section{R. Bras. Zootec., v.33, n.2, p.407-411, 2004}




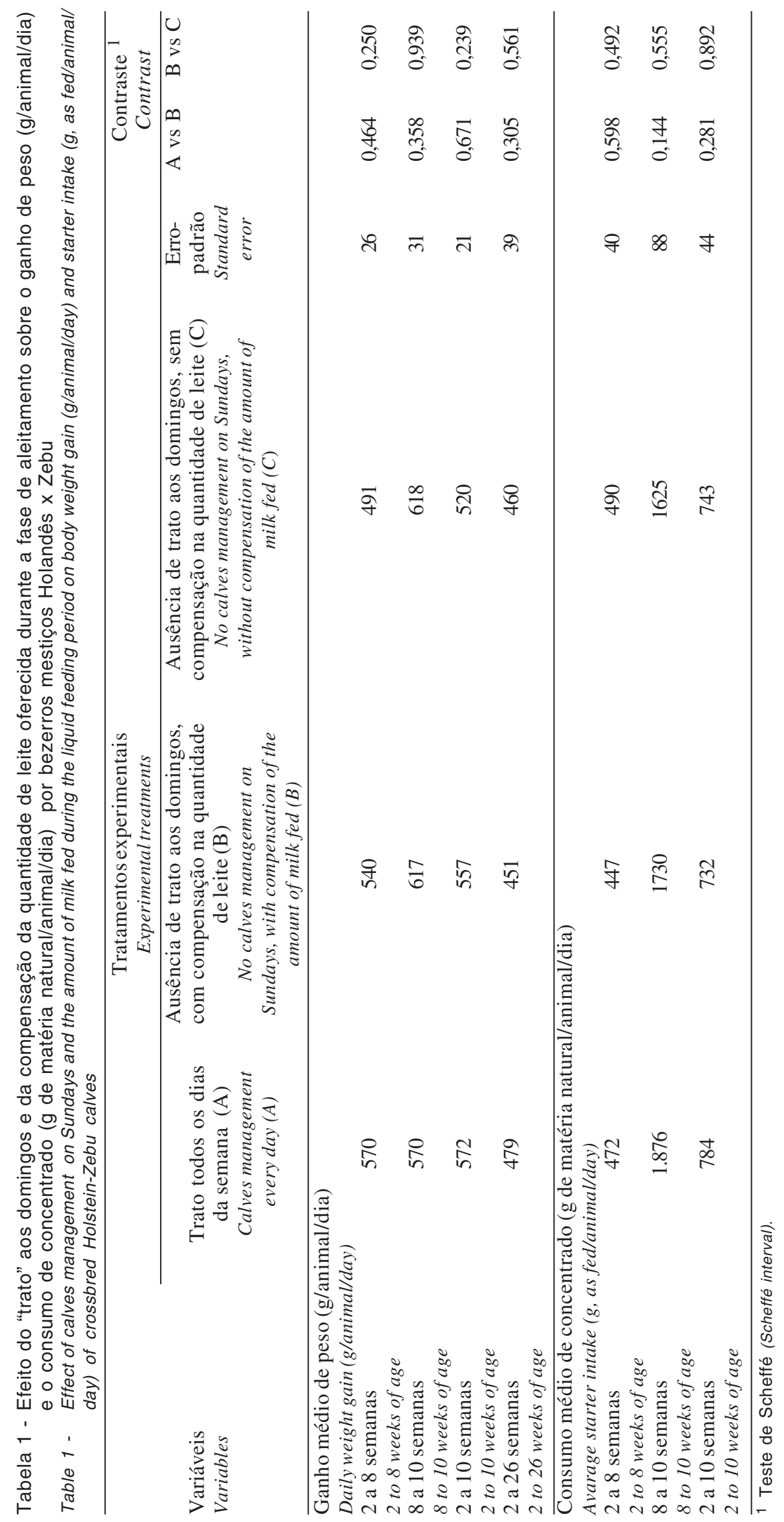




\section{Resultados e Discussão}

Observa-se, na Tabela 1, que não houve diferença significativa $(\mathrm{P}>0,05)$ entre os tratamentos experimentais para ganho médio diário de peso e consumo médio diário de concentrado, nos períodos avaliados, à semelhança dos resultados obtidos por Appleman et al. (1975) e Wood et al. (1971). Desse modo, a adoção desta prática poderá resultar em redução sensível no gasto com mão-de-obra, prevendo-se impacto benéfico no custo de produção de leite. Por outro lado, a ausência de trato dos bezerros aos domingos exige algumas mudanças em paralelo, a saber: o local onde são criados os bezerros em aleitamento deve ser, preferencialmente, isolado de outros locais onde pessoas circulam aos domingos, uma vez que a presença delas pode estressar os animais, que estariam já acostumados àquela rotina, à espera da refeição líquida; maior atenção deve ser dada aos animais nos outros dias da semana, em especial na segunda-feira, para verificar se eles estão bem após o jejum imposto no dia anterior; as aplicações de remédios em animais doentes devem prever este novo manejo.

A análise dos pesos vivos dos bezerros a cada semana, durante as primeiras dez semanas de vida, cujos resultados são mostrados na Tabela 2, revelou que os animais alimentados com menor quantidade de leite apresentaram pesos significativamente menores que aqueles submetidos aos tratamentos controle ou com compensação no sábado e na segunda-feira, da terceira à décima semana; contudo, o peso vivo aos seis meses de idade foi semelhante para os três tratamentos. Este mesmo resultado foi verificado por Boucque et al. (1971). Do ponto de vista prático, tal resultado sugere que, para fazendas com bom manejo, alimentação e mão-de-obra, pode-se considerar a possibilidade de não compensar o leite que os bezerros deixaram de beber no domingo, uma vez que isto representaria redução de 10 a $15 \%$ na quantidade de leite gasta na alimentação desses animais. Em propriedades onde o manejo, a alimentação e a mão-deobra apresentam problemas, melhor seria compensar o leite não oferecido no domingo, uma vez que os animais que não receberam esta compensação se mostraram mais leves, em princípio mais susceptíveis a doenças.

A ocorrência de diarréias independeu do tratamento experimental (Tabela 3), não sendo registrados problemas sérios mesmo naqueles animais que recebiam mais leite aos sábados e às segundas-feiras. Semelhantemente, não foram observadas diferenças entre os dias sob medicação.

Tabela 2 - Efeito do "trato" aos domingos e da compensação da quantidade de leite oferecida durante a fase de aleitamento sobre o peso vivo $(\mathrm{kg})$ de bezerros mestiços Holandês x Zebu

Table 2 - Effect of calves management on Sundays and the amount of milk fed during the liquid feeding period on crossbred Holstein $x$ Zebu calves body weight $(\mathrm{kg})$

\begin{tabular}{|c|c|c|c|c|c|c|c|c|c|c|c|}
\hline \multirow[t]{2}{*}{$\begin{array}{l}\text { Tratamentos experimentais } \\
\text { Experimental treatments }\end{array}$} & \multicolumn{11}{|c|}{$\begin{array}{l}\text { Semanas de idade } \\
\text { Weeks of age }\end{array}$} \\
\hline & 0 & 1 & 2 & 3 & 4 & 5 & 6 & 7 & 8 & 9 & 10 \\
\hline $\begin{array}{l}\text { Trato todos os dias da semana } \\
\text { Calves management every day }(A)\end{array}$ & $34,0^{\mathrm{a}}$ & $36,3^{a}$ & $39,2^{a}$ & $42,1^{\mathrm{a}}$ & $45,0^{\mathrm{a}}$ & $49,4^{\mathrm{a}}$ & $54,2^{a}$ & $59,7^{\mathrm{a}}$ & $64,3^{\mathrm{a}}$ & $70,6^{a}$ & $72,3^{a}$ \\
\hline $\begin{array}{l}\text { Ausência de trato aos domingos, } \\
\text { com compensação na quantidade } \\
\text { de leite } \\
\text { No calves management on Sundays, } \\
\text { with compensation of the amount } \\
\text { of milk fed }(B)\end{array}$ & $34,6^{\mathrm{a}}$ & $36,6^{\mathrm{a}}$ & $38,5^{\mathrm{a}}$ & $41,2^{\mathrm{a}}$ & $44,6^{\mathrm{a}}$ & $48,7^{\mathrm{a}}$ & $53,0^{\mathrm{a}}$ & $58,6^{\mathrm{a}}$ & $63,0^{\mathrm{a}}$ & $68,9^{a}$ & $71,7^{\mathrm{a}}$ \\
\hline $\begin{array}{l}\text { Ausência de trato aos domingos, sem } \\
\text { compensação na quantidade de leite } \\
\text { No calves management on Sundays, } \\
\text { without compensation of the amount } \\
\text { of milk fed }(C)\end{array}$ & $33,9^{a}$ & $34,1^{\mathrm{a}}$ & $36,5^{\mathrm{a}}$ & $38,6^{b}$ & $41,0^{\mathrm{b}}$ & $44,7^{b}$ & $49,8^{b}$ & $53,1^{b}$ & $58,2^{b}$ & $63,5^{b}$ & $66,9^{b}$ \\
\hline
\end{tabular}

Médias com sobrescritos diferentes, na coluna, diferem entre si $(P<0,05)$ pelo teste Tukey.

Means, within a column, with different superscripts are different $(P<.05)$ by Tukey test. 
Tabela 3 - Efeito do "trato" aos domingos e da compensação da quantidade de leite oferecida durante a fase de aleitamento sobre a ocorrência de diarréias em bezerros mestiços Holandês x Zebu

Table 3 - Effect of calveskeeper presence on Sundays and the amount of milk fed during the liquid feeding period on crossbred Holstein $x$ Zebu calves diarrhea occurrence

\begin{tabular}{lccc}
\hline \multirow{2}{*}{$\begin{array}{l}\text { Tratamentos experimentais } \\
\text { Experimental treatments }\end{array}$} & \multicolumn{2}{c}{$\begin{array}{c}\text { Número de dias } \\
\text { Number of days }\end{array}$} & $\begin{array}{c}\text { Totais } \\
\text { Totals }\end{array}$ \\
\cline { 2 - 3 } & $\begin{array}{c}\text { Fezes normais } \\
\text { Normal feces }\end{array}$ & $\begin{array}{c}\text { Diarréia } \\
\text { Diarrhea }\end{array}$ & \\
\hline $\begin{array}{l}\text { Trato todos os dias da semana } \\
\text { Calves management every day }\end{array}$ & 542 & 26 & 568 \\
Ausência de trato aos domingos & 528 & 40 & 568
\end{tabular}

com compensação na quantidade de leite

No calves management on

Sundays, with compensation of the amount of milk fed

Ausência de trato aos

domingos, sem compensação

na quantidade de leite

No calves management on

Sundays, without compensation

of the amount of milk fed

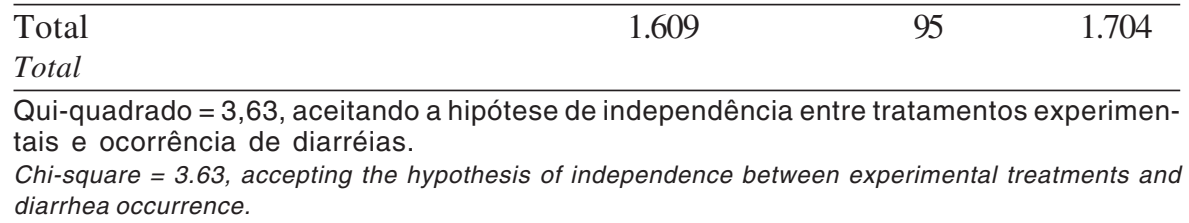

diarrhea occurrence.

\section{Conclusões}

A ausência de trato dos bezerros de rebanhos leiteiros, um dia da semana, não influenciou negativamente no peso dos bezerros aos seis meses de idade, no consumo de concentrado e na ocorrência de diarréias dos animais até os 70 dias de idade. A compensação do leite não fornecido no dia de folga do tratador resultou em maiores pesos dos bezerros ao desaleitamento, mas não aos seis meses de idade.

\section{Literatura Citada}

APPLEMAN, R.D. Breeding, housing and feeding management. Journal of Dairy Science, v. 58, n.3, p.447-464, 1975.

BOUCQUE, C.H.; BUYSSE, F.X.; COTTYN, B.G. The effect of giving 11 or 14 feeds of milk substitute per week to early-weaned calves. Animal Production, v.13, n.4, p.613-618, 1971 .
GOMES, F.P. Curso de estatística experimental. 13.ed. São Paulo: Nobel, 1990. 467p.

WOOD, A.S.; BAYLEY, H.F.; MACLEOD, G. K. Evaluation of imposing weekly fast on calves receiving a milk replacer diet once and twice daily: protein and energy utilization. Journal of Dairy Science, v.54, n.3, p.405- 412, 1971. 